\title{
The Effect of Task-Based Syllabus on Iranian EFL Learners
}

\author{
Mahbobeh Rahmati \\ Islamic Azad University, Tehran, Iran \\ mahbobeh60rahmati@gmail.com
}

\begin{abstract}
The present study is an attempt to explore the effect of different task-based syllabus on Iranian EFL Learners' Oral courses in Terms of Accuracy, Fluency. The outcome of this study could show a light on designing tasks with applicable level of cognitive complexity. The construct of task complexity and its importance in grading and sequencing of pedagogic tasks are discussed. Then, mention will be made of different models and criteria for estimating task complexity. After that, the most comprehensive model (Robinson's Triadic Framework or The Cognition hypothesis) will be discussed in great details. Furthermore, the outcome may prove insightful visions for material producers in preparing tasks and for learners in evaluating their promotion. A questionnaire was assembled for teachers to explore the teaching/learning environment and any problematic areas in this process. Finally, the role of the Task Complexity in grading and sequencing pedagogical tasks will be touched upon.
\end{abstract}

Keywords: complexity; accuracy; task-based syllabus; EFL learners; syllabus design

\section{Introduction}

Among all the four skills (listening, speaking, reading, and writing), speaking seems intuitively the most important one. It is believed that people who know a language are referred to as 'speaker' of that language as if speaking includes all other skills. Besides, many language learners are primarily interested in learning to speak. Therefore, the ability to speak a language fluently is considered as knowing that language because speech is the most basic means of human communication. Speaking is a productive skill. The ability to speak a language fluently demands a lot of time and energy. Effective speakers need to be able to process language in their own heads and put it in coherent order so that it is not only comprehensible but also can convey the intended meaning. One of the main reasons for including speaking activities in language is to help students develop the habits of rapid language processing. Language processing involves the retrieval of words and phrases from memory into syntactically and propositionally appropriate sequence. Apart from our response to others' feeling, we need to be able to process the information in the moment we get it. The longer it takes us to respond, the less effective we are as instant communicator (Ur, 1996).

Researchers such as Skehan (1998) and Robinson (2001) have been eager to find out if the level of task structure and cognitive complexity has any noticeable impact on learners' oral production. This subject has been always controversial since the degree to adjust the task, according to learners' ability has always attracted the researchers' attention. There is a general support to the claim that planning and other factors such as cognitive complexity of the task have crucial impact on oral production (Crookes, 1989; Ellis, 1987; Foster \& Skehan, 1996; Mehnet, 1998; Ortega, 1989, \& Wendel 1997, cited in Ellis 2003). Task complexity and the role it plays in task-based performance are of significant interest to both second language acquisition (SLA) researchers and language teachers. The design of a task has seen as an enormous growth of interest in recent years (Bygate, Skehan, \& Swain, 2001; Ellis, 2003; Garcia Mayo, 2007; Long \& Crookes, 1992; Robinson \& Gilabert, 2007; Samuda \& Bygate, 2008, as cited in Revesz, 2011).

Material producers, researchers, and language teachers have focused on the importance of tasks. However, they have used them in different ways. Some of them have incorporated 
tasks in traditional language. Others have viewed them as units of teaching and have designed whole courses around them. In Ellis (2003), ways of using tasks can be referred to as tasksupported language teaching and task-based language teaching. In both cases tasks can make language teaching more communicative

Iwashita et al. (2001) tried to define oral ability based on the characteristics of tasks since according to them oral ability is not well defined by differences in task difficulty. They refer to Skehan's (1998) statement regarding task dimensions and performance conditions influencing task difficulty. Among the factors mentioned by Skehan (1998), time pressure and degree of visual support are significant. Other aspects of performance conditions may affect task difficulty in a more complicated way; tasks which need more intentional demand may influence not only task difficulty, but also particular aspects of the tasks (Iwashita et al., 2001).

\section{Review of Literature}

One of the most important ideas to emerge from these studies is that where one uses language is less relevant for language learning that what one uses it for, e.g. task. However, before we can claim to have fully established support for adopting a task-based approach for the new program, it is necessary to discuss what is meant by "task" and what makes task-based syllabus? Fundamentally different from earlier types of syllabuses. A number of different definitions or descriptions of "task" have been proposed. However, they all contain the common view that TBLT is an approach (not a method but the center of methodological focus) with an emphasis on developing a second language learner's pragmatic competence by organizing a course around the communicative tasks that learners engage in outside the classroom.

In a comprehensive definition of the term language, speaking plays an important role. Although productive practice does not necessarily contribute to learning, it does foster retention which is an important part of learning. Furthermore, speaking gives students the opportunity to choose reactions and to elicit new information from the people to whom they are talking. This opportunity also motivates students to learn during reading and listening activities. Hence, speaking plays a vital role in learning to use language to communicate. Besides, Speaking is the performance of the speakers' competence, but performance does not follow competence automatically (Chastain, 1998).

Richards (1990, as cited in Celce-Murica, Dorneyi \& Thurrell, 1997) argues that there are two major approaches to teaching speaking skills, an indirect approach, in which conversational competence is seen as the product of involving learners in conversational interaction, and a direct approach, which involves planning a conversational program around the specific micro skills strategies and processes that are involved in fluent conversation. He continues that the indirect approach, which was the typical teaching practice for communicative language teaching (CLT), involves setting up and managing lifelike communicative situations in the language classroom (e.g., role play, problem-solving tasks, or information-gap activities) and directing learners to acquire communicative skills incidentally by seeking meaning. The direct approach, on the other hand, reminds us of traditional methods of teaching grammar where new linguistic information is practiced explicitly.

One of the main aims of CLT is to provide opportunities for learners to take part in interaction where the main purpose is to exchange meaning rather than to learn the L2. The Interaction Hypothesis advanced by Long (1983, as cited in Fonts \& Ellis, 1991) claims that 
the comprehensible input helps to make grammatical features salient for learners and as a consequence learners can acquire the language better. Long (1992) emphasizes the importance of interactional adjustment in two-way communication. Information exchanges with the aim of resolving communication problems are believed to promote acquisition. Although Long (1992) does not make the distinction between explicit and implicit knowledge, it is clear from his writing that by "acquisition" he refers to implicit knowledge. Elsewhere, Ellis (2006) suggests that implicit and explicit knowledge of L2 can be presented in terms of six principle dimensions. These are summarized in terms of how the two types of knowledge are represented and how they are processed for learning and language use: A. Representation dimensions: a) awareness b) type of knowledge c) systematicity of L2 knowledge B. Processing dimensions: a) accessibility of knowledge b) use of L2 knowledge c) self- reported) learn ability.

Howatt (1984, as cited in Richards \& Renandya, 2002) distinguishes between a "strong" and a "weak" versions of CLT. The weak version emphasizes the importance of providing learners with opportunities to use their language for communicative purpose. The strong version of communicative teaching, on the other hand, maintains that language is acquired through communication. So, the former can be described as 'learning to use', the latter entails 'using to learn'. The distinction between these two versions parallels task-supported language teaching and task-based language teaching. The weak version views tasks as a way of providing communicative opportunities for the language items that have been introduced in a more traditional way. The strong version, however, considers tasks as a means of motivating learners to learn a language by experiencing how it is used in communication. In strong version, tasks are both necessary and sufficient for learning while in weak version tasks are necessary but not sufficient for language curriculum.

Jeon and Hahn (2006) express that task-based language teaching has a substantial implication in the area of language learning. They maintain that learning is a developmental process with the aim of promoting communication and social interaction rather than acquiring a product by practicing language items. Besides, they believe that learners learn the target language more effectively when they are naturally exposed to meaningful task-based activities. Such a view of language learning has led to a proper framework for communicative classroom.

Based on Richards' and Renandya's (2002) statement, learners should be actively engaged in communication strategies such as clarification, confirmation, comprehension check, requests, repairing, reacting, and turn taking. Mutual comprehension is what enables learners to move forward in their interlanguage development. So, Learners can actively learn these strategies in the part of their learning process.

Tasks which motivate learners to negotiate meaning are more useful for interlanguage development. Engaging in negotiation produces higher degree of comprehension which leads to more tuned input. Besides, exploration of new hypotheses about the structure of target language will promote flexibility in learners' production (Skehan, 1998, as cited in Richards \& Renandya, 2002). Based on Richards and Renandya (2002), several conditions have significant effect on negotiation of meaning. To name a few, inclusion of pair and group interaction, twoway tasks, and convergent tasks, which require participants to come to a single solution, can promote negotiation of meaning. 


\section{Research Method}

According to Fulcher (2003), one of the main purposes of language learning is to speak without hesitation, linguistic errors, and fragmentation; that is learners wish to use a language in a way that their speeches appear fluent, accurate, and pragmatically effective. In order to reach this goal, we need to examine the contribution of linguistic knowledge and different task types to language production. Fulcher believes that learners cannot develop their L2 proficiency unless they have an opportunity to experience different types of tasks. Furthermore, he maintains that the tasks need to be tailored based on the level of learners' proficiency.

\section{Discussion}

The rise of CLT has had a profound effect on syllabus design. The assumption that communication is an integrated process rather than a linear accumulation of discrete structures and items created a dilemma for syllabus designers, whose task has traditionally been to produce ordered lists of structural items graded according to difficulty, frequency, or pedagogic convenience. But as Breen (1984) points out, the adoption of a communicative view of language teaching compelled designers to prioritize the route of learning as well as the destination. This has resulted in a number of different syllabus design proposals, including notional/functional, situational, topical, and task-based as designers attempt to cope with the problem of basing syllabuses on processes rather than on products. Recently, task-based syllabuses have been receiving the most attention from the research community. In this paper, the trends in CLT which have led to the evolution of task-based syllabuses will be examined and an attempt will be made to provide some justification for their current prominence.

\subsection{A Closer Analysis of the Major Tasks}

Three Dimensions for the analysis of tasks are suggested by Skehan (1998, as cited in Richards \& Renandya, 2002). The first dimension is code complexity which includes linguistic complexity and variety, vocabulary load and variety, and finally redundancy and information density. The problem associated with code complexity can be solved by encouraging learners to use various types of support, such as preparing them for in-class discussion by introducing the details of upcoming tasks. In this case, the level of task difficulty can be adjusted for the learners involved in the task activity. This type of support makes learners feel that they are encountered with reasonable challenge in the task activity. Besides, due to lack of attentional capacities, learners are willing to cope with cognitive demands of tasks with appropriate level of difficulty.

The second dimension, cognitive complexity, is associated with the type of thinking needed for accomplishing the task. The first aspect is cognitive familiarity which consists of topic familiarity, topic predictability, familiarity with the discourse genre, and familiarity with the task. The second aspect, cognitive processing, includes the organization of the information, the amount of needed computation, and the clarity of the information provided. One way to reduce the cognitive complexity is to present brief description and outlines of the task.

The third dimension, communicative stress, is associated with these factors: time limits and time pressure, the speed of presentation, the number of participants involved in the task, the length of the task which is used, the type of expected response, and the ability of learners in 


\subsection{Pedagogic Classification}

Pedagogic classification of tasks found in Gardner and Miller (1996, as cited in Ellis, 2003) serves as a basis for incorporating the task's construct into a traditional language course. The disadvantage of choosing this approach is that based on Ellis (2003), tasks will become more like exercises focusing on discrete aspects of language. In this case, tasks will fail to serve their main aims which are providing learners with authentic language. Willis (1996, as cited in Richards \& Rodgers, 2001) offers a different pedagogic classification of tasks based on an analysis of tasks commonly found in textbook materials. He argues that in this way, learners can generate a variety of actual tasks. This classification reflects the types of activities which learners are involved in while performing the tasks:

1. Listing: This classification is used when the completed outcome is a list.

2. Ordering and sorting: Tasks that involve sequencing, ranking, categorizing, or classifying items would be set in this classification.

3. Comparing: Tasks that involve finding the similarities or differences in information can be placed in this group.

4. Problem solving: Tasks that require intellectual activity such as puzzles can be defined in problem solving category.

5. Sharing personal experiences: This group is associated with tasks that allow learners to share their experiences and to talk freely about themselves.

6. Creative tasks: These tasks often involve several stages; they can incorporate various types of tasks.

\subsubsection{Cognitive Classification.}

A cognitive approach to classifying tasks is based on the cognitive operations that tasks involve. Based on the kind of cognitive activity, Prabhu (1987, as cited in Ellis, 2003 \& Nuan, 2005) proposes three general types of tasks:

Information gap activity: This type of activity involves a transfer of given information from one person to another or from one form to another. This kind of activity calls for encoding or decoding of information. One example is pair work in which each member of the pair has a part of the total information and attempts to transfer it to the other person. Hence, information gap refers to the existence of a lack of information among participants working on a common problem.

Reasoning gap activity: This type of activity includes deriving some new information through the process of inference, deduction, practical reasoning, or a perception of relationship and patterns. An example is a task that requires students to work out a teacher's timetable from a set of class timetables.

Opinion-gap activity: Based on Prabhu (1987, as cited in Ellis, 2003 \& Nunan, 2005), opinion-gap activities are associated with identifying and articulating a personal preference, feeling, or attitudes in response to a given situation. Story completion and discussion are some examples of opinion-gap activity. Such tasks are open in the sense that they offer many possible solutions and learners can negotiate and choose the best option.

High-level oral performance in L2, demands a cognitive processing system that functions properly. Two such cognitive factors include lexical access and attention control. Speed and efficiency of lexical access demonstrate the degree to which learners' speeches are free from self-generated filled pauses. Besides, shifting attention from one aspect of speech to another can slow the overall speech rate in learners, because learners need to self-monitor their speech. 
On the whole, learners' ability to make use of different opportunities is different linguistically and cognitively (Segalowitz \& Freed, 2004).

\subsubsection{Psycholinguistic Classification.}

A psycholinguistic classification of tasks is designed to establish a typology in relation to language learning. In fact, different tasks can complement each other when different aspects of language use are considered as the criterion. Pica, Kanagy, and Faladon (1993, as cited in Ellis, 2003) suggest a system according to the Interaction Hypothesis. The system is 'psycholinguistic' in the sense that it is based on interactional categories that have been proved to affect the ways learners have to comprehend input, obtain feedback, and to modify their own output. The categories are:

1. Interaction relationship: This is associated with a person who holds the information to be exchanged and the one who requests it and supplies it in order to reach the goal of the task. This relationship is associated with one-way and two-way tasks. The essence of this relationship is based on the negotiation of meaning when there is a mutual relationship between requests and preparation.

2. Interaction requirement: This concerns whether task requires participants to request and supply information or if it is optional. Research has shown that the negotiation of meaning is enhanced if all participants take part in the interactional activity.

3. Goal orientation: Tasks that require collaboration (convergence) lead to more negotiation of meaning than tasks which allow for independence (divergence).

4. Outcome options: This refers to the scope of the task's outcomes available to the participant when meeting the task goals; in 'closed' tasks a single outcome is required while in 'open' tasks there are several possible outcomes.

\subsubsection{Features and Characteristics of Tasks}

Certain design features are associated with focused or unfocused tasks:

Input: Based on Nunan (2005), input refers to the spoken, written, and visual data that learners are involved in while completing a task. To Nunan (2005), data can be provided by a teacher, a text book, or by learners themselves. Whereas Nunan identifies input as a task component, Ellis (2003) distinguishes two separate components, 'input' and 'conditions'. He maintains that we need to distinguish between the kind of input that a task provides, for example, whether it is verbal or non-verbal, and the way in which the data are presented. These constitute two quite distinct task variables. So, while the tasks may have the same input, for example, a set of pictures telling a story, they may include different conditions, for instance, the pictures could be seen by all the participants or they could be delivered among them.

Another way of analyzing the procedures is in terms of their focus or goal. One way of characterizing procedural goal is whether they are skill getting or skill using. In skill getting tasks, learners try to master phonological, lexical, and grammatical forms through memorization and manipulation while in skill using tasks they apply these skills in communicative interaction (Rivers \& Temperley, 1978, as cited in Nunan, 2005).

Based on Iwashita et al. (2001), the three main approaches to the task characterization are interactional approach, information-processing approach, and test-method approach. The first approach defines the interactional characteristics of tasks and its effect of dyadic communication among learners. The second approach, the information processing approach, is associated with the cognitive characteristics of tasks and task difficulty. In third tradition, test task characteristics are clarified as test-methods. 


\subsubsection{Syllabus Types}

"Syllabus" and "curriculum": two poles of a dichotomy, about which definitions have diverged and still do. Different views to explain what a syllabus is are held by various linguists and specialists. Stern (1983: 434), for instance, holds that curriculum is a general term that covers "the entire instructional process" while syllabus, for him, means a list of content to be taught in a course. Yalden (1987:86) advocates that a syllabus is an instrument to link learners' needs and aims to activities that take place in the classroom. Willing (1988, in Nunan 1988) as well, surveys the class and asks them which aspects they like best. Breen (in Nunan 1988) says that 'syllabus' has a broader sense and means the expression of belief, i.e. the psychology of learning, how a class is taught, and even the social development of learners. Munby (1978, in Nunan 1988), in another view, records in a syllabus the actual ability of learners, the purpose from learning the target language and situations expected in the course. Nunan and Burton (1985, in Nunan 1988) rather focus on the students and what type of program will suit each individually.

Different types of learning exist; and thus, they have to be delicately considered in syllabus construction. Gagne (1965: 58-58 in Brown 2000: 92) identifies eight types of learning: Signal , stimulus-response, chaining, verbal association, multiple discrimination, concept, principle, and problem solving. And, for Brown (1995: 142) there are seven common syllabuses: Structural, Situational, Topical, Functional, Notional, Skills, and Task or activitybased. He quotes Johnson (1978: 46 \& 1981: 34) to point that there are simply different ways to organize a course and teachers are only expected to use their professional judgment to combine or adjust them.

\section{1) The Structural Syllabus}

Also known as the traditional syllabus, it is organized along grammatical items giving primacy to language form. The structural syllabus holds the theory that functional ability arises from structural knowledge. Structural patterns, organized according to such criteria as structural complexity, difficulty, regularity, utility and frequency, are the basic units of learning. It makes an abundant use of highly controlled, tightly structured and sequenced pattern practice drills. It deals with Semantics and sentence types such as statements, questions, interrogatives and grammatically defined types such as simple, compound and complex sentences are seen. Morphology can also be found in structural syllabi such as singular, plural marking; determiners, articles, prepositions, gender markers and so on. In a structural syllabus, Grammar constitutes a familiar and frequently expected content, and according to it, grammatical concepts such as nouns, imperatives, plural, gerund are simply better defined than functional ones and also easily measured. Wilkins (1976) redefines the language content of the structural syllabuses through the following items:

- The notions or concepts the learners need to talk about,

- The functional purposes for which language is used,

- The situations in which language would be used, and

- The roles the learners might possibly play.

One other feature of the structural syllabus is its supposed generative aspect. Having learnt paradigms and pattern sentences, learners are supposed to be able to use this knowledge to generate their own sentences and express their own meanings. However, students generally spend years at schools learning the grammar of the foreign language and finally are unable to generate anything personal. Willis (1996) argues that the potential is there if the right conditions are provided. 


\section{2) The Process Syllabus}

The Process Syllabus is an approach to syllabus design sometimes thought of as 'task-based' or 'procedural' (McDonough \& Shaw 1993: 60). It focuses on the language learning process and the contributions of the learner to it (Breen 1987: 159). It takes into account decisions and alternative procedures, activities and tasks for the classroom group. It addresses teaching and learning explicitly and makes possible the interrelationships between subject matter, learning and the potential contributions of a classroom. The provided framework is one in which a predesigned content syllabus is publicly analyzed and evaluated by the classroom group, and the content is designed in an on-going way. In other words, this syllabus accepts the evolving nature of competence and adapts as it emerges gradually. In some cases, learners are encouraged to choose for themselves, but with guidance, which ways to follow through loads of activities and materials, motivated by their own interest.

A similar approach was based on tasks in Prabhu's (1987) procedural syllabus consisting of: information, reasoning, or opinion, gap activities. Materials were not completely pre-constructed but were merely prompts for tasks that developed from the learners themselves.

\subsection{Skehan's Model of Task Difficulty}

The main objective of researchers has been to identify a set of task characteristics based on the assumption that learner's performance varies according to the task characteristics. Recent research has been examined how different task types can influence the quality of the learners' outcome in classroom setting. To Skehan (1998, as cited in Taguchi, 2007), three factors contribute to task difficulty: code complexity (the syntactic and lexical difficulty of language input), cognitive complexity (the processing demands of tasks such as memory and attention), and communicative stress (time pressure and the modality demand). These psycholinguistic factors are considered to produce different demands, and hence can affect the quality of the learners' performance.

Planning time, included in Skehan's model of communicative stress, is another psycholinguistics factor in task difficulty. The assumption is that the quality of the production depends on efficient planning. Previous research has examined the effect of planning time on L2 output. Planning time would lead learners to produce more accurate and fluent speech as well as higher level of lexical complexity. However, in terms of accuracy results are different. Some studies showed that more accurate speech might be due to certain task types while others proved that task condition is an influential factor which determines the degree of accuracy. For instance, anxiety in learners may lead to less accurate oral production (Iwashita et al., 2001). Based on Skehan's (1998) model, planning time positively influence linguistic output. The previous studies operationalized task difficulty mainly from a psycholinguistic perspective. The findings showed that tasks with greater cognitive demands affect L2 spoken output in terms of accuracy, fluency, and complexity.

Skehan (1998, as cited in Iwashita et al., 2001) suggests a number of factors which have impact on task difficulty. Based on him, task dimensions such as abstractness of task information and familiarity of task are held to affect the difficulty of the task. He maintains that performance conditions (e.g., concrete vs. abstract information) play a crucial role in determining the level of task difficulty. Table 2.2 depicts the factors which have influence on task difficulty. 
Among all factors, time pressure and the degree of visual support are likely to affect task difficulty in a particular way. Other aspects of performance conditions may affect task difficulty in a more complex way, in that tasks emphasizing particular types of attentional demand may have a measurable impact not on task difficulty as a whole but on particular aspects of the performance. Tasks and performance conditions that direct attentional resources to forms and rules may induce "risk-avoiding" or "risk-taking" behavior. These tasks produce variation in measures of accuracy and complexity of language. On the other hand, tasks that direct attentional resource to meaning and real time processing have been found to produce variation in measure of fluency (Iwashita et al., 2001).

Table 1. Factors Affecting Task Difficulty (Skehan, 1998)

Performance conditions

\begin{tabular}{llc}
\hline & Less difficult & More difficult \\
\hline $\begin{array}{l}\text { Number of participants or elements } \\
\text { Abstractness of information or task }\end{array}$ & $\begin{array}{l}\text { few } \\
\text { concrete } \\
\text { Type of task information }\end{array}$ & $\begin{array}{c}\text { many } \\
\text { retrieval }\end{array}$ \\
$\begin{array}{l}\text { Nature of operation required } \\
\text { on task information }\end{array}$ & familiar & $\begin{array}{c}\text { there-and then } \\
\text { transformation }\end{array}$ \\
Familiarity of task information & & unfamiliar \\
\hline
\end{tabular}

\subsection{Robinson's Task Complexity Dimension}

Over the past few years, due to the use of interactional task in L2 classroom, investigating the factors affecting learners' oral production has been the core of research studies (Kim, 2009). For instance, based on Cognition Hypothesis stated by Robinson (2001a, as cited in Kim, 2009), engaging learners in complex tasks facilitates their oral performance. Elsewhere, Kim (2009) states that task type and learners' proficiency are two prominent factors which effect learning opportunities and oral production significantly.

Robinson (2001a, 2001b, 2003, 2005, as cited in Kim, 2009) defines sources of a task's cognitive demand as: (1) task complexity-cognitive factors, (2) task condition-interactional factors, and (3) task difficulty-learners factors. Based on his framework, two dimensions are identified: resource- directing and resource dispersing. Task complexity is defined as resourcedirecting and resource-dispersing variables. Requiring learners to perform more than one task simultaneously stimulates real world performance conditions. In this case, task complexity is increased along resource-dispersing dimensions. On the other hand, while increasing task complexity along resource-directing dimension, for example, by requiring learners to reason about and/ or refer to many elements instead of a few, we direct learners' attention to specific L2 constructions in the L2 relevant to the suitable cognitive domain (Robinson, 2001a, 2005, as cited in Revesz, 2011). Resource-directing variables of task complexity require great demands on attention and working memory; these variables make learners focus on linguistic form. Examples of resource-directing factors are: [ \pm few elements], [ \pm here and now], and [ \pm reasoning]. The low complexity conditions include [+ few elements], [+ here and now], and [- reasoning] while the high complexity conditions are [- few element], [-here and now], and [+reasoning]. However, based on Robinson (2001a, 2005, as cited in Kim, 2009), resourcedispersing variables are those that make more demands on participants' memory resources. Therefore, based on Robinson (2005, as cited in Kim, 2009), increasing task complexity along 
recourse-dispersing dimensions disperse learners' attention over many non-specific linguistic areas of the L2. Some examples of resource-dispersing factors include: [ \pm planning], [ \pm single task], and [ \pm prior knowledge]. In other words, the low complexity conditions are [+planning], [+single task], and [+prior knowledge] while high complexity conditions include [-planning], [-single task], and [-prior knowledge]. According to Robinson (2005, as cited in Kim, 2009), the Cognition Hypothesis shows that complex tasks may produce L2 production with more accuracy and linguistic complexity, but with less fluency. Complex tasks produce interactional processes such as corrective feedback and noticing of input. Kim (2009) argues that in Cognition Hypothesis, L2 linguistic performances as well as interactional processes such as noticing and learning opportunities are taken into account. Kim (2009) states that teachers should consider learners' proficiency and task type while making a decision on suitable task complexity level during task-based teaching.

\subsubsection{Task Complexity, Focus on Form-Meaning Mapping and Interaction}

The research attention has been extended to recognizing task variables that can promote interaction-driven opportunities. In these opportunities, learners attempt to draw attention to L2 form-meaning connection in the context of meaning-based communication which has been termed as language-related episode (LRE). By now, it has been discovered that a great deal of task variables can impact the quantity and quality of negotiation and/ or LREs (Revesz, 2011). Furthermore, more cognitively interactive tasks (along both resource-directing and resourcedispersing dimensions) are likely to result in greater communicative demands. In this case, more communication breakdowns may occur, thus larger amount of negotiation for meaning is needed. In addition to negotiation sequences, manipulating task complexity has impact on the quantity of LRE initiated by linguistic needs. Manipulating task complexity can increase attention to L2 form-meaning mappings (Robinson, 2001a, as cited in Revesz, 2011). Revesz (2011) argues that when learner' attention is more directed to L2 construction, they tend to draw their interlocutors' attention to linguistic features even when understanding among them is not an issue.

According to Trade-Off Hypothesis, more complex tasks lead to fewer opportunities for LREs, because learners need to devote more attentional resources to content and hence, less would be available for language. The prediction for the effects of increasing task complexity along resource-dispersing dimensions in Robinson's model seems to be the same. However, when task complexity is increased, learners tend to direct their attention to task-relevant construction and linguistic elements (Revesz, 2011).

\subsubsection{Measuring Learner's Production in Terms of Accuracy, Fluency, and Linguistic Complexity}

Learners' production can be measured either by means of external ratings or discourse analytic measures. In general, language testers have preferred the former and SLA researchers have considered the latter. External ratings are based on scales that specify the specific competency and levels of performance for each competence. While measuring task-based performance, the target competence can be specified either in behavioral terms that reflect the degree to which the learners have successfully completed the task or in linguistic terms. In the case of discourse analytic measures, two types of measures are possible, measures of specific linguistic features and measures of general dimensions of oral discourse (Ellis, 2003). Table 2.3 classifies some of the specific measures used in terms of fluency, accuracy, and complexity. 


\section{Conclusion}

According to the results of this study it could be felt that Iranian EFL learners have difficulty producing a fluent and accurate speech. To solve this problem, we need a comprehensive insight into methodology in general and designing and adjusting the level of tasks in particular.

Based on the findings, the group who performed more cognitively difficult tasks was more successful in terms of accuracy and linguistic complexity; therefore, the first and third null hypotheses were rejected; however, in the case of fluency, considering "reasoning demands" element, the group who performed easier task got better result. This decline could perhaps be associated with anxiety and probably other individual factors. Checking fluency along "number of elements" and "here-and-now vs. there-and-then" condition proved no significant discrepancy between the two groups' performance, hence, the second null hypothesis was accepted. These findings confirm the beneficial impact of increasing task cognitive complexity on speaking specially in accuracy and linguistic complexity. This in turn can be an acceptance for Robinson's Cognition Hypothesis with his emphasis on the promotion of learners' oral skills along with increasing the cognitive complexity of the task.

\section{References}

Bachman, L. F. (2005). Statistical analysis for language assessment. (2nd ed.). Cambridge: Cambridge University Press.

Chastain, k. (1998). Developing second-language skills: theory and practice. (3 ${ }^{\text {rd }} \mathrm{ed}$.), Florida: Harcourt Brace Jovanovich, Inc.

Celce-Murica, M., Dornyei, Z., \&Thurrell, S. (1997). Dirrect approaches in L2 instruction: A turning point in Communicative Language Teaching? TESOL Quarterly, 31 (1), 141-152.

Ellis, R. (2000). Task_based research and language pedagogy. Language Teaching Research, 4(3), 193-220.

Ellis, R. (2003). Task-based language learning and teaching. Oxford: Oxford University Press.

Ellis, R. (2005). Planning and task performance in second language, Philadelphia: John Benjamins.

Fahim, M. (2011). The effect of task characteristics on L2 learners' production of complex, accurate, and fluent oral language. International Journal of Education, 3(2).

Fulcher, G. (2002). Task difficulty in speaking tests. Language Testing, 20(3), 321-344.

Foster, P, \& Skehan, P. (1996). The influence of planning and task type on second language performance. Studies in Second Language Acquisition, 19, 199-323.

Iwashita, N., McNamara, T., \& Elder, C. (2001). Can we predict task difficulty in an oral proficiency test? Exploring the potential of an information- processing approach to task design. Language Learning, 51(3), 401-436.

Kim, Y. (2009). The effect of task complexity on learner-learner interaction. System, 37, 254268.

Long, M. (1992). Three approaches to task-based syllabus design. TESOL Quarterly, 26(1), 27-55.

McGraw, H. (2006). The official guide to the new TOEFL IBT. New York, NY: Author.

Murphy, J. (2003). Task-based learning: The interact between task and learners. ELT Journal, $57(4)$.

Nunan, D. (2005). Task-based language teaching. Cambridge: Cambridge University Press. 
Revesz, A. (2011). Task complexity, focus on L2 construction, and individual differences: A classroom- based study. Modern Language Journal, 162-181.

Robinson, P. (1995). Attention, memory, and noticing hypothesis. Language Learning, 45(2), 283-331.

Robinson, P. (1996). Task complexity and second language narrative discourse. Language Learning, 45(1), 99-140.

Robinson, P., (2001). Task complexity, task difficulty, and task production: exploring interactions in a componential framework. Applied Linguistics, 22, 27-57.

Robinson, P. (2005). Cognitive complexity and task sequencing: Studies in a componential framework for second language task design. International Review of Applied Linguistics, 43, 1-32.

Skehan, P. (1996a). A framework for the implementation of task-based instruction. Applied Linguistics, 17, 38-62. http://dx.doi.org/10.1093/applin/17.1.38

Skehan, P. (2003). Task-based instruction. Language Teaching, 39 (1), 1-14. 